\title{
District-level energy matching tool for carbon-free concepts
}

\author{
Ari Laitinen ${ }^{1}$, Francesco Reda ${ }^{1}$, Ala Hasan ${ }^{1}$ \\ ${ }^{1}$ VTT Technical Research Centre of Finland Ltd, Espoo, Finland
}

\begin{abstract}
The aim of this paper is to describe the development of an energy-matching assessment tool that can be used to study different innovate energy concepts in new districts based on existing distribution infrastructure (district heating and cooling). The objective is to demonstrate carbon free energy concepts based on renewable energy sources. District energy concept includes heating, cooling and electricity. Studied renewable energy sources are wind and solar electricity combined with ground or air source heat pumps, solar heat and heat recovery options from waste water and cooling energy of the buildings. The studies include also batteries and heat storages. Storage capacities are convertible from daily to seasonal.

The tool makes assessment of the energy self-sufficiency and the level of autonomy of a district. Different types and capacities of renewable technologies for heat and electricity energy generation and storage can be investigated to reach the set target of self-sufficiency.

The utilization of the tool is demonstrated with a case study. The study includes a large district with total building floor area of $1620000 \mathrm{~m}^{2}$ and energy system that is base only on PV and wind power generation. The study introduces design requirements for the generation and energy storages like batteries and heat storages when aiming at self-sufficient district.
\end{abstract}

\section{Introduction}

At the Paris climate summit, COP21 (http://www.cop21paris.org/), 175 countries signed the Paris Agreement on December $12^{\text {th }} 2015$, committing to reduce the global temperature well below 2 degrees to alleviate the effects of climate change. As a follow up during the Global Climate Action Summit (https://www.globalclimateactionsummit.org/) at the COP 24 (https://cop24.gov.pl/news/), local and regional governments strongly asked clear procedures for implementing Paris Agreement rules. European Commission responded to these tightening the climate goal for 2050 with the "2050- long-term strategy" (https://ec.europa.eu/clima/policies/strategies/2050_en) calling for a prosperous, modern, competitive and climate-neutral economy by 2050.60 to $80 \%$ of global energy consumption and around the same share of $\mathrm{CO}^{2}$ emissions is generated in urban areas (https://ec.europa.eu/clima/policies/international/paris_p rotocol/cities en). There are a wide range of solutions for reducing the carbon footprint and improving the energy efficiency of urban areas and cities are naturally wellpositioned to embrace the energy transition towards a cleaner future (https://www.iea.org/newsroom/news/2016/september/ci ties-are-at-the-frontline-of-the-energy-transition.html). Many tools have been developed for planning of community scale energy systems considering many RES and other energy generation sources (Lyden 2018) However up to author knowledge, these do not consider well established energy matching indicators for planning energy efficient buildings and neighbourhoods (Huovila 2016). These indicate the portion of the district energy demand covered by the local renewable production (onsite energy fraction- OEF) and the portion of the generated renewable local energy consumed within the district boundaries instead of being exported. The benefit of using these indicators lies on the intuitive and easy understanding of the overall energy performance of the district infrastructure. The ideal case would be to have high OEF and high OEM. In this case, the district energy demand is fully covered by the local RES (Renewable Energy System) without any export of energy or, in other words, any stress on the city electrical network.

Authors developed a tool building on such matching indicators. The tool is supposed to be used by planners and designers as first instrument for planning a carbonfree district.

Important to notice that, in the absence of feed-in tariff and energy incentives, energy export price from buildings to the grid is lower than the energy import price. This means that energy matching by using the onsite produced energy to cover the current and future energy demand will avoid buying energy at a higher price. In addition, this will support the concept of self-sufficiency in the community. However, this implies that the types and capacitates of the onsite production and storages should support achieving these targets.

In the case study, described later on, we will consider a system where the electricity and the heating loads of a district is covered by electrical generation from PV and wind. The system includes batteries to store surplus electricity and also storage tanks to store surplus heat. The electricity distribution is bi-directionally connected to the grid, which means that electricity can be exported when there is excess power generation or imported when needed. There can also be bi-directional connection 
between the on-site heat distribution system and the district heating network but in our case study, the only offsite connection is to the electrical grid.

\section{Operation logic of the energy system}

The topology of the system is presented in Figure 1.

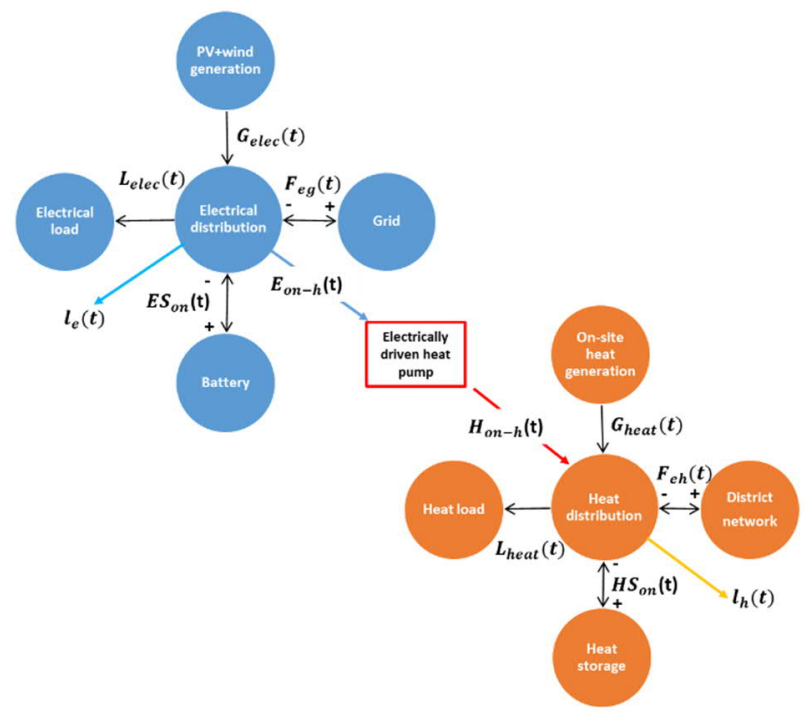

\section{Figure 1: Topology of the matching indices for} electricity and heating.

The nomenclature of the electrical system includes $G_{\text {elec }}(t)$, which is the electrical power generation of the PV and wind plants, $L_{\text {elec }}(t)$ is electrical load which in our case study contain also the electrical load of the chiller, $E S_{\text {on }}(t)$ is charging (+) or discharging (-) power of the battery system, $E_{o n-h}(t)$ is electricity used to run heat pumps to cover the heating needs, $F_{e g}(t)$ is exported $(+)$ or imported (-) electricity from the grid and $l_{e}(t)$ is losses from the electrical distribution system. The heating system side includes $G_{\text {heat }}(t)$ which covers on site heat generation (in our case study there is no extra heat generation), $H_{o n-h}(t)$ is heat generated by electrically driven heat pump run by surplus electrical generation of the PV and wind plants, $L_{\text {heat }}(t)$ is the heat load of the district, $H S_{o n}(t)$ is charging $(+)$ or discharging (-) power of the heat storage, $F_{e h}(t)$ is exported $(+)$ or imported (-) heat power of the district network and $l_{h}(t)$ is losses of the heat distribution.

The operation logic of the case study is to first cover the electrical load $L_{\text {elec }}(t)$ by the PV and wind generation $G_{\text {elec }}(t)$. When there is surplus electricity, it is stored to the batteries. When the batteries are full, the excess electricity $E_{o n-h}(t)$ is used to run the heat pumps to generate heat $H_{o n-}$ ${ }_{h}(t)$. If there is still excess electricity, it is exported to the grid $+F_{e g}(t)$. When the electrical load is not covered by PV and wind generation, the needed power is discharged from the batteries $-H S_{o n}(t)$ and if it is not enough, the shortfall is covered by imported electricity from the grid $-F_{e g}(t)$. The heat side operation is similar but the difference is that there is no on-site heat generation $G_{\text {heat }}(t)$. First the heat demand $L_{\text {heat }}(t)$ is covered by the heat generation of the heat pumps $H_{o n-h}(t)$. If there is surplus heat, it is used to charge the heat storage $+H S_{\text {on }}(t)$. If there is still excess heat, it can be exported to the district heating network
$+F_{\text {eh }}(t)$. In our case study we operate the system so that heat is produced only enough to cover the heat load and to fill the heat storage which means that excess electricity is exported to the grid and there is no heat to export. In practice the choice to export electricity or heat would be based on economical or environmental reasons. When the heat generation of the heat pumps $H_{o n-h}(t)$ is not enough to cover the heat load $L_{\text {heat }}(t)$, the heat storage is discharged $-H S_{o n}(t)$ and when even this is not enough, heat is imported from the district network $-F_{e h}(t)$.

\section{Matching analysis}

The quantification of the energy matching is done by using the cover factors: on-site energy fraction and on-site energy matching indices. These indices are formulated using the nomenclature introduced in Figure 1 (Cao, Hasan and Sirén, 2013). The on-site energy fraction $(O E F)$ and the on-site energy matching for electricity $(O E M)$ are

$$
\begin{gathered}
\text { OEFe }=\frac{\int_{t_{1}}^{t_{2}} \operatorname{Min}\left[G_{\text {elec }}(t)-E S_{\text {on }}(t)-l_{e}(t) ; L_{\text {elec }}(t)+E_{\text {on-h }}(t)\right] d t}{\int_{t_{1}}^{t_{2}}\left[L_{\text {elec }}(t)+E_{\text {on-h }}(t)\right] d t} \\
O E M e=\frac{\int_{t_{1}}^{t_{2}} \operatorname{Min}\left[G_{\text {elec }}(t) ; L_{\text {elec }}(t)+E_{\text {on-h }}(t)+E S_{\text {on }}(t)+l_{e}(t)\right] d t}{\int_{t_{1}}^{t_{2}} G_{\text {elec }}(t) d t}
\end{gathered}
$$

and for heating

$$
\begin{gathered}
O E F h=\frac{\int_{t_{1}}^{t_{2}} \operatorname{Min}\left[G_{\text {heat }}(t)-H S_{\text {on }}(t)-l_{h}(t) ; L_{\text {heat }}(t)\right] d t}{\int_{t_{1}}^{t_{2}} L_{\text {heat }}(t) d t} \\
O E M h=\frac{\int_{t_{1}}^{t_{2}} \operatorname{Min}\left[G_{\text {heat }}(t)+H_{\text {on-h }}(t) ; L_{\text {heat }}(t)+H S_{\text {on }}(t)+l_{h}(t)\right] d t}{\int_{t_{1}}^{t_{2}}\left[G_{\text {heat }}(t)+H_{\text {on-h }}(t)\right] d t}
\end{gathered}
$$

The on-site energy fraction index $(O E F)$ indicates the amount of the energy demand covered by the on-site energy generation. The on-site energy matching index $(O E M)$ describes the amount of the on-site energy generation used on-site to cover the demand. To illustrate the electrical indices, an example of the behavior of the PV and wind generation, electrical load, electricity used for heating and surplus electricity as well as charge of the batteries for the case under study are given for one day in Figure 2. Total PV and wind electricity generation presents green line and load red line, purple is total surplus electricity generation, yellow the part of the surplus electricity that is used for heat generation and black the imported electricity from the grid and black dotted exported electricity to the grid. The state of charge of the batteries is presented with dotted blue line. It can be seen that there is surplus electricity generation roughly until 17:00 o'clock after which the batteries are discharged and when they run empty electricity is imported from the grid to cover the demand. Part of the surplus electricity is converted to heat by heat pumps (yellow line) but not all, so there is excess electricity to export to the grid (black dotted line). 


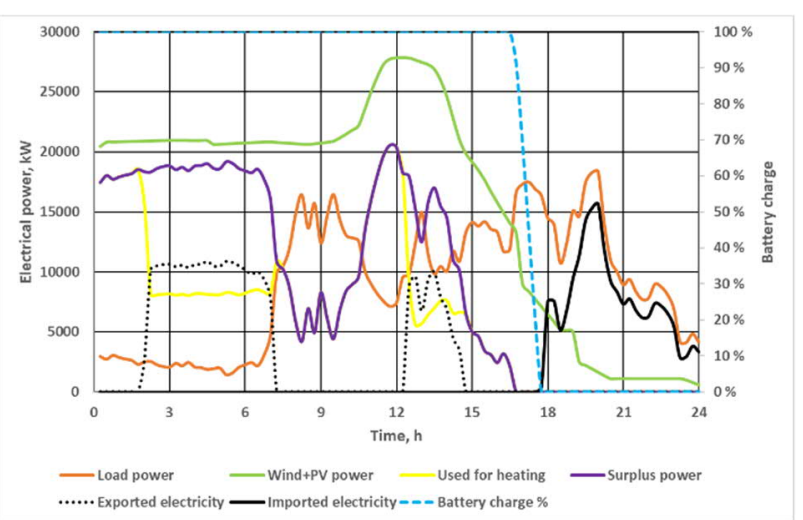

Figure 2: Example case to illustrate electricity indices. Green is total PV\&wind electricity generation $\left(G_{\text {elec }}(t)\right)$, red is load $\left(L_{\text {elec }}(t)\right)$, purple total surplus electricity $\left(G_{\text {elec }}(t)-L_{\text {elec }}(t)\right)$, yellow is the part of the surplus electricity that is used for heating $\left(E_{\text {on-h }}(t)\right)$ and blue is state of charge of the batteries.

The dynamic indices for electricity (OEFe and OEMe) presented in Figure 3 has been calculated using the equations (1) and (2) as well as the data presented in Figure 2.

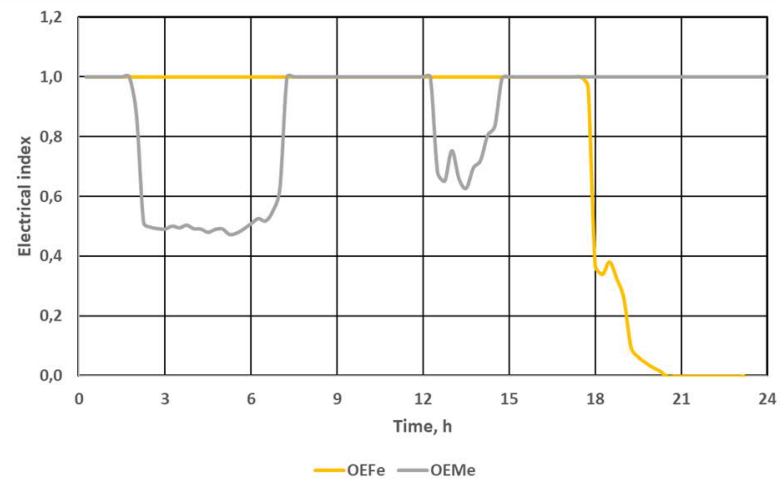

Figure 3: On-site electrical indices OEFe and OEMe specified by the example presented in figure 2. On-site energy fraction $(\mathrm{OEFe})$ drops when there is no $P V \&$ wind generation and the charged battery energy has all been used and the shortfall electricity has to be imported from the grid. The on-site energy matching index $(O E M e)$ drops when there is excess electricity that has to be exported to the grid.

\section{Description of the tool}

The new developed tool (EnFloMatch) is sought to be simple, but at the same time able to capture the performance of different types of energy demands, production and storages.

The importance of energy matching quantification in a district stands on the indication of its energy selfsufficiency and independency from the central grids towards being autonomous. The developed tool suits best concept analysis in the early design phase to answer questions like: what is the required system design based on renewable energy to cover the seasonal energy needs for a district? The tool is scalable from one single-family house level to urban (large districts) level. It is easy to make different energy generation combinations and play with dimensioning and boundaries of the system like:

- Battery or/and heat storage capacities

- Dimensioning of PV, wind, heat pump generation

- heat sources of the heat pump

- COP of heat pump and EER of cooling

In the analysis, the quantification of the energy matching is illustrated by using energy cover factors (energy demand cover factor and energy generation cover factor), which include different options for energy generation, conversion and storage of electricity, heating and cooling. The tool is built in Excel and it post-processes data produced by building performance simulation tools (e.g. TRNSYS and IDA ICE). The approach is to simulate and aggregate different energy demand profiles (heat demand, cooling demand and electricity) in a bottom-up approach and then add to those profiles in Excel some special loads that do not interfere with the building loads such as electric car charging loads to generate the total demand profiles for the whole community. The demands of the community can be created from different building types (apartment buildings, offices and schools). In addition to the generated demand profiles, the simulation tools are also used to create production profiles, such as solar heat, $\mathrm{PV}$ and wind electricity production profiles. In our analysis, we use 15 minutes time step for both the energy demand and production profiles. Then, the matching of the demands and productions are calculated in Excel where also energy storages can be combined to the analysis. Electricity can be stored in batteries including losses in charging and discharging processes as well as self-discharge. Surplus heat from solar collectors and possible heat pumps can be stored in hot-water storages, which can be tanks or cavern heat storages. The capacities of the batteries and heat storages can be freely chosen so that they can be either small daily or big seasonal storages. A description of the developed tool is presented in Figure 4.

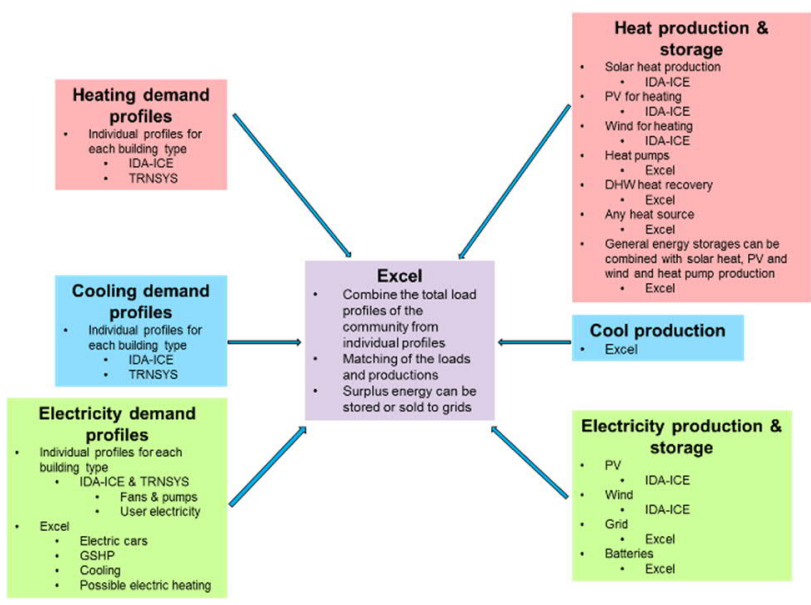

Figure 4: Schematic description of the developed tool for the district level energy analysis. 


\section{Electricity}

The electricity balance between the demand, renewable electricity generation from $\mathrm{PV}$ and wind, storage (batteries) and export/import from the grid, can be presented for each time step as

$$
L_{\text {elec }}-G_{\text {elec }}-E_{\text {on- } h}-E S_{\text {on }}-F_{\text {eg }}=0
$$

$L_{\text {elec }}$ is electricity demand, $G_{\text {elec }}$ is on-site electricity production from $\mathrm{PV}$ and wind power, $E_{o n-h}$ is electricity to heat generation, $E S_{\text {on }}$ is electricity from (-) or to batteries $(+)$ and $F_{e g}$ is electricity from (-) or to grid (+).

Balance of the batteries include losses during charging, discharging, and self-discharge. Here we assume that the efficiency during charging and discharging are equal $\left(\eta_{B}\right.$ $=88 \%$ ). The charge of the batteries at each time-step is

$$
\begin{gathered}
E_{c h}=\min \left(E_{c h, \text { max }}, E_{c h-1}-D_{B}+E S_{\text {on }} \eta_{B} \Delta t\right), \\
G_{\text {elec }}>L_{\text {elec }} \\
E_{c h}=\min \left(E_{c h-1}-L_{B}, E_{\text {ch-1 }}-D_{B}-E S_{\text {on }}\left(2-\eta_{B}\right) \Delta t\right), \\
G_{\text {elec }} \leq L_{\text {elec }}
\end{gathered}
$$

$E_{c h, \text { max }}$ is maximum capacity of the battery $(\mathrm{kWh}), E_{c h-l}$ is charge of the battery at previous time-step $(\mathrm{kWh}), D_{B}$ is self-discharge losses $(\mathrm{kWh})$ and and $\Delta t$ is used time step (h). The charging energy of the battery is lower than the surplus energy from PV and wind generation due to losses so the charging energy $\left(E_{B}\right)$ should be multiplied by the efficiency $\eta_{B}$. The same goes also for the discharging energy, which is multiplied by the factor $\left(2-\eta_{B}\right)$. This means that we have to discharge the battery more than actually is needed because of the losses.

Often the charging and discharging efficiency is given as round-trip efficiency which means that the total efficiency from fully charged battery to fully discharged and back to fully charged. In this case the efficiency used in charging and discharging phases is (HOMER)

$$
\eta_{B}=\eta_{R}{ }^{0,5}
$$

$\eta_{B}$ is efficiency during charging and discharging phases and $\eta_{R}$ is the round-trip efficiency of the battery storage.

\section{Heating}

The heat balance can be written using the same nomenclature as in Figure 1 as:

$$
L_{\text {heat }}-G_{\text {heat }}-H_{\text {on-h }}-H S_{\text {on }}-F_{\text {eh }}=0
$$

Here $L_{\text {heat }}$ is heat demand $(\mathrm{W}), G_{\text {heat }}$ is on site heat production by thermal way, $H_{o n-h}$ is on-site heat generation based on electrical production, $H S_{o n}$ is charging (+) or discharging (-) power of the thermal storage and $F_{\text {eh }}$ is heat to (+) or from (-) the district heating network.

The heat energy of the storage at each time step when only envelope heat losses are considered is

$$
\begin{gathered}
Q_{c h}=\min \left(Q_{c h, \text { max }}, Q_{c h-1}-D_{S}+H S_{\text {on }} \Delta t\right), \\
G_{\text {heat }}+H_{\text {on-h }}>L_{\text {heat }} \\
Q_{c h}=\min \left(Q_{c h-1}-E_{h}, Q_{c h-1}-D_{S}-H S_{\text {on }} \Delta t\right), \\
G_{\text {heat }}+H_{\text {on-h }} \leq L_{\text {heat }}
\end{gathered}
$$

Here $Q_{c h, \max }$ is maximum capacity of the heat storage (kWh), $Q_{c h-l}$ is the capacity of the heat storage at previous time-step $(\mathrm{kWh}), D_{S}$ is envelope heat losses $(\mathrm{kWh}), H S_{\text {on }}$ is charging $(+)$ or discharging (-) heat power $(\mathrm{kW})$ and $\Delta t$ is used time step $(\mathrm{h})$.

\section{Case study}

The aim of the studies is to find concepts for carbon free district based on renewable energy sources. Renewable energy sources include photovoltaic and wind power to cover seasonal electricity loads combined with batteries and ground or air source heat pump with heat storage to cover the seasonal heat demand of the district. The idea is also to utilize innovative heat recovery techniques such as domestic hot water and cooling loads for the heat source of the heat pumps. This conference paper covers only part of the total number of case studies carried out. The comprehensive results of the research will be published in a journal paper in the near future.

\section{Case description}

All the studies have been carried out with fixed district plan in Finland. The typology of the district consists of apartment buildings, offices and schools. The total building areas of the community (Table 1) mimics the Kalasatama district of Helsinki, which is under construction. The district in our studies is supposed to be built as energy efficient district with better insulation and HVAC systems technologies than the present building regulations demand in Finland (Table 2). Special attention

\begin{tabular}{|c|c|c|}
\hline Construction & $\begin{array}{c}\text { Apartment } \\
\text { building }\end{array}$ & $\begin{array}{c}\text { Office and } \\
\text { school }\end{array}$ \\
\hline $\begin{array}{l}\text { External walls, U-value } \\
\qquad \mathrm{W} /\left(\mathrm{m}^{2} \mathrm{~K}\right)\end{array}$ & 0.10 & 0.10 \\
\hline 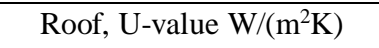 & 0.07 & 0.07 \\
\hline Floor, U-value $\mathrm{W} /\left(\mathrm{m}^{2} \mathrm{~K}\right)$ & 0.11 & 0.11 \\
\hline Windows, U-value $\mathrm{W} /\left(\mathrm{m}^{2} \mathrm{~K}\right)$ & 0.70 & 0.7 \\
\hline $\begin{array}{l}\text { Exhaust air heat recovery } \\
\text { rate, - }\end{array}$ & 0.7 & 0.7 \\
\hline $\begin{array}{l}\text { Air infiltration, } \mathrm{m} 3 /(\mathrm{h}, \mathrm{m} 2- \\
\text { ext. wall) }\end{array}$ & 0.1 & 0.05 \\
\hline
\end{tabular}
has been paid to the simulation of the apartment building in order to present the behavior of the whole district with only one simulated building. In particular, individual energy consumption profile of home appliances for each apartment, and internal gain due to appliances and people presence, has been set as in Reda (2019).

Table 1. Data of the studied district.

\begin{tabular}{|c|c|c|c|}
\hline Building type & $\begin{array}{c}\text { Floor area, } \\
\mathrm{m}^{2}\end{array}$ & $\begin{array}{c}\text { Roof area, } \\
\mathrm{m}^{2}\end{array}$ & $\begin{array}{c}\text { Electric } \\
\text { car plots }\end{array}$ \\
\hline Apartment & 1200000 & 171429 & 3077 \\
\hline School & 20000 & 6667 & 33 \\
\hline Office & 400000 & 33333 & 667 \\
\hline Total & 1620000 & 211429 & 3744 \\
\hline
\end{tabular}

Table 2. U-values of the constructions and air infiltration. 
The energy system consists of electrical generation from renewable sources $(\mathrm{PV}+$ wind generation) connected to battery system. The heating system consists of ground source heat pumps connected to the heat storages. There is also bi-directional connection to electrical grid. This means that the energy system is like presented in Figure 1 but slightly simplified i.e. there is no on-site heat generation $\left(G_{\text {heat }}(t)\right)$ and no district heating network $\left(F_{e h}(t)\right)$. The PV-panel installation has been varied between $0 \%, 50 \%$ and $100 \%$ of the total roof coverage $(0,15 \mathrm{kWp}$ and $30 \mathrm{kWp})$.

Total heating demand of the community is $97,3 \mathrm{GWh}$ which is a combination of space heating (47 \%), ventilation $(6 \%)$ and domestic hot water $(47 \%)$ demands. The yearly variation of the heating load is presented in Figure 5 with 15 minutes resolution.

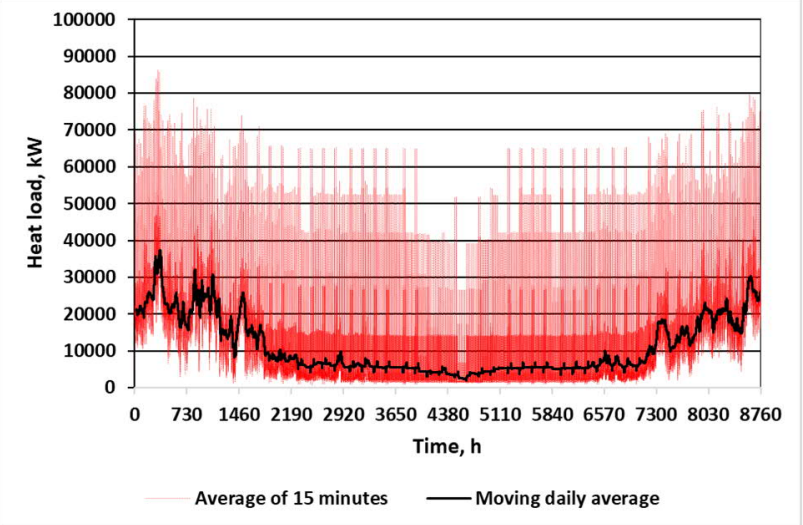

Figure 5: Heating load of the case district.

Total cooling demand of the community is $10,5 \mathrm{GWh}$ of which space cooling covers $74 \%$ and ventilation $26 \%$. Offices covers $51 \%$ and apartments $49 \%$ of the cooling load so there are practically no cooling demand in schools which is due to long summer holiday from the early June until the start of August. Electricity consumption of the cooling is added to the electricity load by presuming COP of cooling $=3$. Cooling load is presented in Figure 6 with 15 minutes resolution.

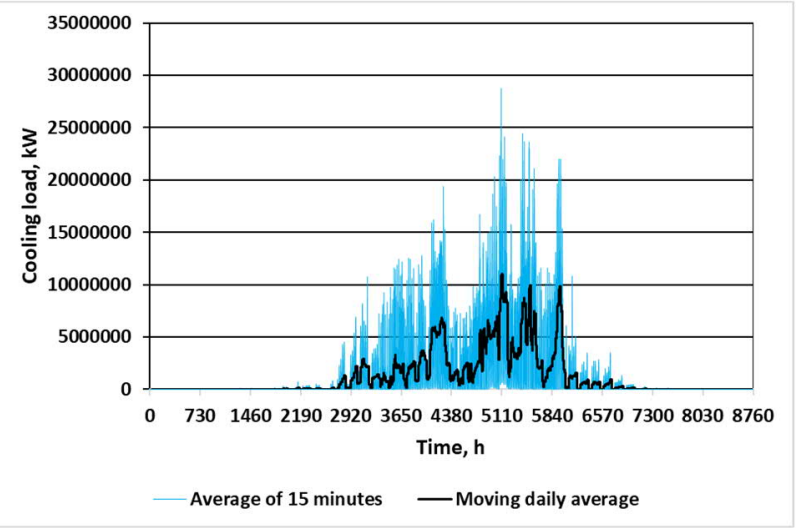

Figure 6: Cooling load of the Kalasatama district.

Yearly electricity consumption of the community is 72,7 GWh including user loads, fans, pumps, electric vehicle and cooling demands (Figure 7). In the case study it is supposed that the cooling load is covered by conventional chiller plant which seasonal energy efficiency ratio
(SEER) is 3. Yearly electrical load is presented in Figure 7 with 15 minutes resolution.

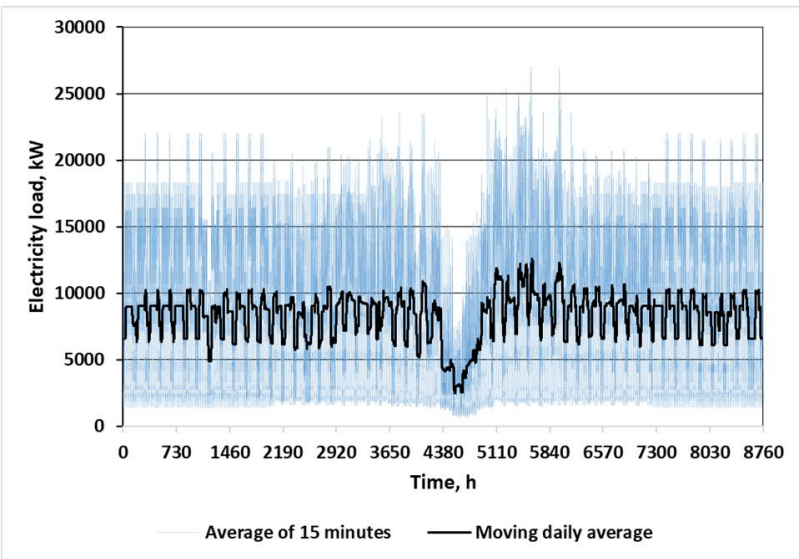

Figure 7: Electricity load of the Kalasatama district.

\section{Results}

Preliminary results reveal that one possible system combination to build a carbon free community would require that in addition to cover all available roof space with PV panels (coverage $100 \%$, nominal power 30 $\mathrm{MWp}$ ) it would require 4 off-shore, 140 meters high, wind turbines with $5 \mathrm{MW}$ of rated power (total power capacity $20 \mathrm{MW}$ ) and battery capacity of $700 \mathrm{MWh}$. The electricity production of this system would cover $100 \%$ of the seasonal electricity, cooling and heating demands of the community provided that the heating system was based on heat pumps (ground and/or air source) combined with the capacity of $35 \mathrm{GWh}$ thermal storage. This system combination will also produce $13,5 \mathrm{GWh}$ of surplus electricity or $37,8 \mathrm{GWh}$ thermal energy if the excess electricity is converted to thermal energy with the heat pumps.

The case has also been studied with smaller PV-panel installations covering $0 \%, 50 \%$ of the roof area and with variable wind power ranging from $20 \mathrm{MWp}$ to $50 \mathrm{MWp}$ (from 4 generators each $5 \mathrm{MWp}$ to 10 generators each 5 MWp). The aim of the study was to discover the needed battery and heat storage capacities to reach full on-site electrical and heating energy coverage with only PV and wind generation. The results are shown in Figure 8 and Figure 9.

When the roof cover area of the PV is dropped down to $50 \%$ and $0 \%$, the minimum required wind power increases from $20 \mathrm{MWp}$ to $25 \mathrm{MWp}$. With smaller wind generation capacity it is not possible to reach selfsufficiency in the district. Obviously the needed battery and heat storage capacities also increase (Figure 8 ). The surplus electricity by contrast decreases, which is clear when observing the on-site matching indices (Figure 9). 


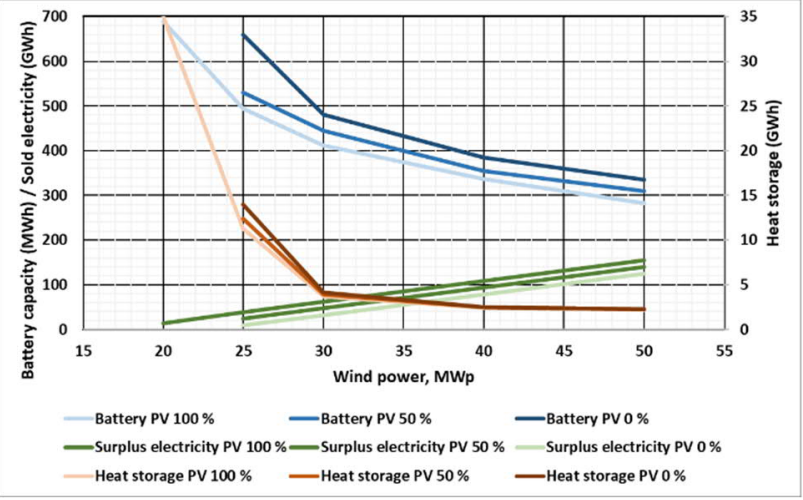

Figure 8: Required battery and heat storage capacity with variable wind electricity production and with three fixed PV generations covering $100 \%, 50 \%$ and $0 \%$ of the roof space ( $30 \mathrm{MWp}, 15 \mathrm{MWp}$ and $0 \mathrm{MWp}$ ) to reach totally (on-site energy fraction $=1$ ) carbon-free district of Kalasatama area.

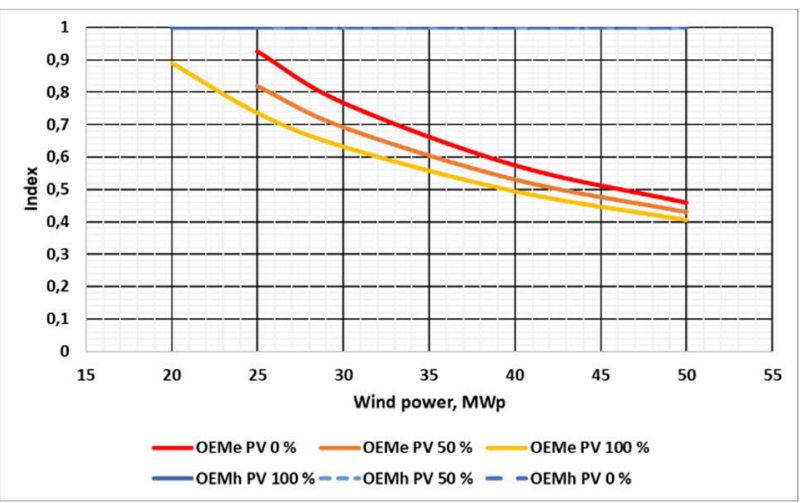

Figure 9: On-site matching indices for electricity and heating as function of installed wind and $P V$ power. The electricity indices depends on the installed PV power: the higher the installed power the lower the index. The heating indices are all $=1$ because it was decided that all excess energy were to be exported as electricity to the grid.

The required capacities of the batteries and the heat storages are huge and the investment costs of the presented solutions would be unrealistic at the present state especially with low wind power installations.

\section{Conclusion}

The developed tool is shown to be simple but sufficient enough to establish energy selection guidance at the early design phase on a district level. The tool can be tailored to different kinds of electricity, heating and cooling loads and to various energy generation combinations.

The developed matching tool were utilized in the presented case study on large district including 1200000 $\mathrm{m}^{2}$ of apartment, $400000 \mathrm{~m}^{2}$ of office and $20000 \mathrm{~m}^{2}$ of school floor areas aimed for demonstrating technical solutions to reach self-sufficiency in regard to electricity, heating and cooling. The case study focus on an energy system based completely on the PV and wind electricity generation. PV and wind electricity is used to cover not only the electricity load including electricity for cooling but also to cover the heat demand with electrically driven heat pumps. Because the electricity production varies along time in large tolerance both batteries and heat storage are needed to cover the cap between production and demand. The studied PV installation sizes are limited to the available roof area and the used coverage rates were $100 \%, 50 \%$ and $0 \%$ of the available roof space. The study revealed that with $100 \% \mathrm{PV}$ case the minimum required wind power capacity is $20 \mathrm{MWp}$ based on offshore turbines. This minimum case would require unrealistic big battery (700 MWp) and heat storage (35 $\mathrm{GWh}$ ) capacities. Increasing the generation capacities it is possible to reduce considerably the required storage capacities. At the same time the district becomes strongly net positive in regard to electricity.

\section{Acknowledgement}

This work was partly funded by The Academy of Finland project "Smart Energy Transition (SET)- Realizing it's Potential for Sustainable Growth for Finland's Second Century, dec. no. 314325".

\section{References}

Cao, S., Hasan, A. and Sirén, K. (2013) 'On-site energy matching indices for buildings with energy conversion, storage and hybrid grid connections', Energy and Buildings. Elsevier B.V., 64, pp. 423-438. doi: 10.1016/j.enbuild.2013.05.030.

HOMER,

https://www.homerenergy.com/products/pro/docs/3.1 1/battery_roundtrip_efficiency.html

Huovila, A., Klobut, K., \& Hyvärinen, J. (2016). New KIPs and tools for planning energy efficient buildings and neighbourhoods. In Proceedings of the 41st IAHS World Congress on Housing, Sustainability and Innovation for the Future

Lyden A., Pepper, R., Tuohy, P.,G., 'A modelling tool selection process for planning of community scale energy systems including storage and demand side management, Sustainable Cities and Society', Volume 39, 2018, Pages 674-688, ISSN 2210-6707, https://doi.org/10.1016/j.scs.2018.02.003.

Reda, F., Fatima, Z., 'Northern European nearly zero energy building concepts for apartment buildings using integrated solar technologies and dynamic occupancy profile: Focus on Finland and other Northern European countries', Applied Energy, Volume 237, 2019, Pages 598-617, ISSN 0306-2619, https://doi.org/10.1016/j.apenergy.2019.01.029. (http://www.sciencedirect.com/science/article/pii/S03 06261919300297) 